\title{
Human mesenchymal stem cell-replicative senescence and oxidative stress are closely linked to aneuploidy
}

\author{
JC Estrada', Y Torres ${ }^{1}$, A Benguría ${ }^{2}$, A Dopazo ${ }^{2}$, E Roche ${ }^{3}$, L Carrera-Quintanar ${ }^{3}$, RA Pérez ${ }^{1}$, JA Enríquez ${ }^{1}$, R Torres ${ }^{4}$, JC Ramírez ${ }^{4}$, \\ E Samper ${ }^{1,6,7}$ and A Bernad ${ }^{*, 1,5,7}$
}

In most clinical trials, human mesenchymal stem cells (hMSCs) are expanded in vitro before implantation. The genetic stability of human stem cells is critical for their clinical use. However, the relationship between stem-cell expansion and genetic stability is poorly understood. Here, we demonstrate that within the normal expansion period, hMSC cultures show a high percentage of aneuploid cells that progressively increases until senescence. Despite this accumulation, we show that in a heterogeneous culture the senescence-prone hMSC subpopulation has a lower proliferation potential and a higher incidence of aneuploidy than the non-senescent subpopulation. We further show that senescence is linked to a novel transcriptional signature that includes a set of genes implicated in ploidy control. Overexpression of the telomerase catalytic subunit (human telomerase reverse transcriptase, hTERT) inhibited senescence, markedly reducing the levels of aneuploidy and preventing the dysregulation of ploidy-controlling genes. hMSC-replicative senescence was accompanied by an increase in oxygen consumption rate (OCR) and oxidative stress, but in long-term cultures that overexpress hTERT, these parameters were maintained at basal levels, comparable to unmodified hMSCs at initial passages. We therefore propose that hTERT contributes to genetic stability through its classical telomere maintenance function and also by reducing the levels of oxidative stress, possibly, by controlling mitochondrial physiology. Finally, we propose that aneuploidy is a relevant factor in the induction of senescence and should be assessed in hMSCs before their clinical use.

Cell Death and Disease (2013) 4, e691; doi:10.1038/cddis.2013.211; published online 27 June 2013

Subject Category: Experimental Medicine

Human mesenchymal stem cells (hMSCs) are proposed as a powerful cell therapy tool for a variety of aging-related and autoimmune diseases. ${ }^{1,2}$ Although hMSCs can be obtained from several tissues, they are scarce in the body. Cell therapy protocols require 10-400 million hMSCs per treatment, and consequently, these cells need to be expanded in vitro for 8-12 weeks before implantation (www.clinicaltrials.gov). The length of this expansion period and the quality of the cells depend on the isolation and culture methods, ${ }^{3,4}$ and are strongly influenced by the patient's clinical history, age and genetic makeup. ${ }^{5,6}$

All primary human cells, including hMSCs, undergo only a limited number of cell divisions under standard culture conditions, in a process called cellular senescence. ${ }^{7}$ Senescence is considered to be a stress response triggered by activation of three main mechanisms: critical telomere erosion, accumulation of DNA damage and derepression of the INK4/ARF locus. ${ }^{8}$ These three processes converge on the activation of the tumor suppressors $P 53$ and $R B$, and all are highly influenced by the oxidative stress inherent to cell culture, leading to stress-induced premature senescence (SIPS). ${ }^{9,10}$

Senescence is characterized by an irreversible state of growth arrest, apoptosis resistance, morphological and cellsize changes, high levels of the tumor suppressors $P 16, P 21$, $P 53$ and/or $R B$, increased activity of SA- $\beta$-gal and loss of the ability to synthesize DNA. ${ }^{11}$ All dividing cultures are heterogeneous populations that initially contain a low percentage of growth-arrested cells, but this percentage increases progressively with passage until most cells become senescent and culture growth flattens. ${ }^{12,13}$

Telomere shortening is one of the best-characterized senescence-triggering mechanisms. ${ }^{14-16}$ Telomeres can shorten during cell-culture expansion in the absence of stress as a result of the end-replication problem (replicative senescence), but the rate of telomere loss can be accelerated by oxidative stress. ${ }^{17,18}$ In most cells, telomere length is maintained by the action of telomerase. ${ }^{19}$ hMSCs have insufficient telomerase activity to overcome the progressive telomere shortening caused by the end-replication problem

\footnotetext{
${ }^{1}$ Department of Cardiovascular Development and Repair, Fundación Centro Nacional de Investigaciones Cardiovasculares Carlos III (CNIC), Melchor Fernández Almagro 3, Madrid, Spain; ' ${ }^{2}$ Genomics Unit, Fundación Centro Nacional de Investigaciones Cardiovasculares Carlos III, Melchor Fernández Almagro 3 , Madrid, Spain; ${ }^{3}$ Unidad de bioquímica y terapia celular, Instituto de Bioingeniería, Universidad Miguel Hernández, Elche, Spain; ${ }^{4}$ Viral Vectors Unit, Fundación Centro Nacional de Investigaciones Cardiovasculares Carlos III, Melchor Fernández Almagro 3, Madrid, Spain and ${ }^{5}$ National Center for Biotechnology, Madrid, Spain

${ }^{*}$ Corresponding author: A Bernad, Department of Cardiovascular Development and Repair, Fundación Centro Nacional de Investigaciones Cardiovasculares Carlos III (CNIC), Melchor Fernández Almagro 3, Madrid E-28029, Spain. Tel: +34 9145312 74; Fax: +34 91453 12 40; E-mail: abernad@cnic.es

${ }^{6}$ Current Address. Nimgenetics SL. Faraday 7, PCM. E-28049 Cantoblanco Madrid, Spain.

${ }^{7}$ These authors share senior authorship.

Keywords: Stem cells; MSC; genetic instability; telomerase; aneuploidy; mitochondrial metabolism

Abbreviations: OCR, oxygen consumption rate; FDR, false discovery rate; TRAP, telomere repeat amplification protocol

Received 19.11.12; revised 07.5.13; accepted 14.5.13; Edited by Y Shi
} 
and oxidative stress associated with culture, resulting in senescence. ${ }^{20,21}$ The importance of telomerase in senescence is demonstrated by the finding that human telomerase reverse transcriptase ( $h T E R T)$ overexpression counteracts replicative senescence and extends lifespan of several types of primary cells, including hMSCs. ${ }^{22,23}$

Telomeres are the termini of eukaryotic chromosomes and their principal function is to protect chromosomes from illegitimate fusion and recombination, thereby preserving genome integrity. ${ }^{24,25}$ Recently, we and other authors showed that a high proportion of long-term cultures of human stem cells show several types of chromosomal abnormalities ${ }^{26-30}$ that could compromise their clinical usefulness. However, in spite of the close relationship between chromosomal alterations and neoplastic processes, spontaneous transformation has not been convincingly demonstrated in long-term cultures of human primary cells. ${ }^{31-34}$

In this article, we show that cellular aneuploidy increases progressively with time in hMSC cultures. hTERT expression and telomere maintenance appear to be crucial for the control of ploidy, and hTERT overexpression has potential as a method for increasing the genetic stability of primary cultures used for cell therapy. Our results further suggest that $h T E R T$, in addition to its role in telomere maintenance, preserves genetic stability by contributing to the control of the oxidative state of the cell.

\section{Results}

In vitro expansion of hMSCs is associated with high levels of aneuploidy. Individual cultures of adiposetissue-derived adult hMSCs $(n=5)$ were maintained under conventional growth conditions until development of replicative senescence. Cultures were able to complete $25.09 \pm 1.6$ population doublings (PD) over 23 passages (Figure 1a). To determine the dependence of adipose-tissue-derived adult hMSC-replicative senescence on telomerase activity, four independent cultures were transduced with a lentiviral vector encoding $h T E R T$. Transduction was confirmed by qPCR TaqMan and Q-TRAP (telomere repeat amplification protocol) assay (Supplementary Figures S1A and S1B), and effective immortalization was corroborated by continued growth capacity over at least 21 passages (Figure 1a). In subsequent experiments, hTERT-MSCs were considered a positive control of non-senescent cells.

The percentage of hMSCs positive for senescence-associated $\beta$-galactosidase activity (SA- $\beta$-gal) increased with passages, from $4.23 \pm 1.6 \%$ at passage 2 to $90.48 \pm 3.29 \%$ at passage 20; in contrast, hTERT-MSCs lacked detectable SA- $\beta$-gal activity even at later passages (Figure 1b). hMSC lifespan was categorized as early passage $(\leq 5)$, middle passage $(>5-10)$ and late passage $(\geq 15)$, according to proliferation ability and the percentage of SA- $\beta$-gal, similarly as previously proposed. ${ }^{35}$

To evaluate senescence at the molecular level, we monitored the expression of the typical senescence markers $P 53, P 21$ and $P 16$ at early-late passages in hMSCs, and at very-late passage (passage $>20$ ) in hTERT-MSCs. Although levels of P53 mRNA and protein were constant in all primary cultures, expression of their downstream-regulated gene
$P 21$ and the senescence marker $P 16$ increased during senescence (Figures 1c and d). hTERT-MSCs maintained lower levels of all markers (mRNA and protein) even at late passage (Figures $1 \mathrm{c}$ and $\mathrm{d}$ ).

To investigate the effects of replicative senescence on genomic integrity, we first analyzed cell cycle profiles at several passages. The results showed that long-term culture is accompanied by a progressive increase in apoptotic cells $(0.75 \pm 0.23$ at early passage to $5.99 \pm 2.63 \%$ at late passage) and arrested cells in G0/G1 phase $(78.17 \pm 1.83-84.47 \pm 3.9)$. Concomitant with this, there was a reduction in the numbers of replicating cells $(7.38 \pm 1.26-2.29 \pm 0.332)$ and in the G2/M subpopulation $(12.47 \pm 1.42-5.11 \pm 1.1)$ (Figure $2 a)$. In all hMSC cultures, the percentage of cells with more than $4 \mathrm{~N}$ DNA content was $<0.30 \%$ (Figure $2 a$ ). Interestingly, hMSCs presented a higher coefficient of variation in G0/G1 and G2/M peaks at advanced passages in culture (Figure 2a), suggesting the presence of abnormal cells with a DNA content not equal to $2 \mathrm{~N}$ or $4 \mathrm{~N}$ (aneuploid); hTERT-MSCs maintained coefficients similar to hMSCs at early passages (Figure 2a). Then, we analyzed the aneuploidy levels in interphase from passages $2-20$ by fluorescence in situ hybridization (FISH). The use of specific centromeric probes for fluorochromelabeled chromosomes 8, 11 and 17 allowed us to distinguish between cells that were diploid (two signals per cell and probe) or aneuploid (more or less than two signals per cell and probe) for each chromosome. A clear tendency was detected toward increased aneuploidy for all analyzed chromosomes. At passage 2, aneuploidy in chromosomes 8,11 and 17 affected $8.07 \pm 0.89,9.15 \pm 0.76$ and $11.74 \pm$ $1.39 \%$ of cells, respectively, and this was increased by passage 20 to $18.65 \pm 3.13,22.05 \pm 2.73$ and $27.56 \pm 2.90 \%$ (Table 1). Most cases of aneuploidy appearing at late passage involved trisomy or tetrasomy for any chromosome (Figure $2 \mathrm{~b}$ ); however, cells triploid or tetraploid for all three chromosomes constituted $<10 \%$ of all aneuploid cells (data not shown), in agreement with results obtained in cell cycle analysis. hTERT-MSCs maintained low levels of aneuploidy even at passage 20 , resembling non-transduced hMSCs at passage 2 (Table 1).

To evaluate whether telomere shortening is critically involved in hMSC-replicative senescence and genetic instability, we monitored the mean telomere length by quantitative $\mathrm{FISH}$ (Q-FISH) in four primary hMSC cultures at passages 2-5 and passages 9-10, and in their hTERT-MSC counterparts at passages 18-22. Consistent with published findings, ${ }^{14,16}$ fluorescent telomere signal significantly decreased between initial and final passages in hMSCs, whereas the hTERT-MSC derivatives contained elongated telomeres (Figure 3a).

Dysfunctional or short telomeres can promote anaphase bridges, dicentric chromosomes and chromatid breaks via fusion-bridge breakage, which contributes to aneuploidy (reviewed in Martinez et al. $^{25}$ ). We carried out a detailed cytogenetic analysis of chromatid breaks and fusions using telomeric and centromeric PNA probes. These experiments showed that hTERT-MSCs have a significantly lower rate of chromosomal abnormalities, with no chromosome fusions or dicentrics and only one break in all the metaphases analyzed, even after culture beyond passage 18 (Figure 3b). 

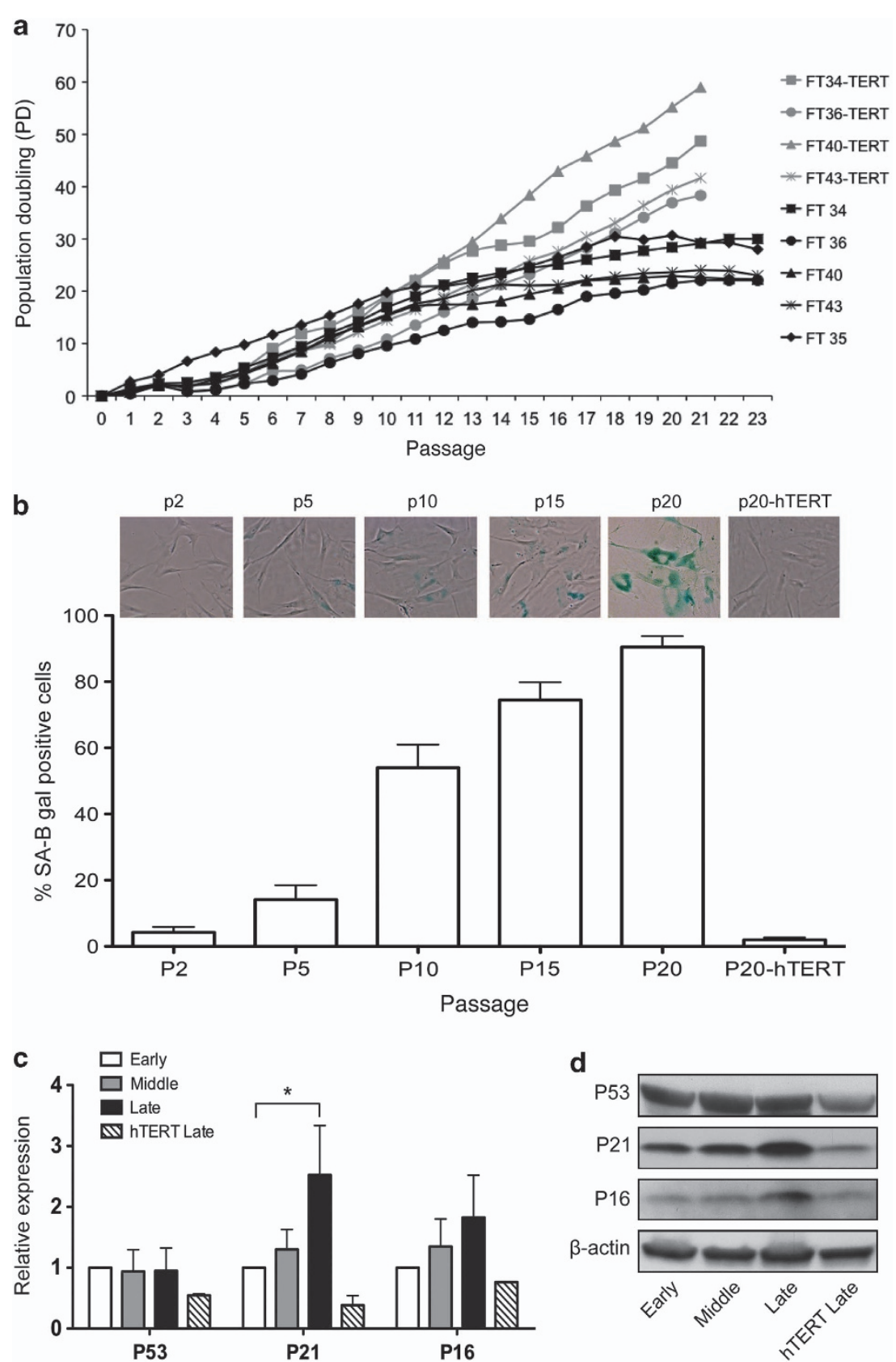

Figure 1 Characterization of hMSCs replicative senescence. (a) Growth curves of five independent primary hMSC samples (black) and four hMSC samples transduced with $h T E R T$ lentiviral vector (hTERT-MSC) at passage 5 (gray). Neither the proliferation rate nor the morphology of hMSCs was significantly changed after 15 passages. No evidence of spontaneous immortalization was observed in any primary cell sample over 23 passages. (b) Percentage of SA- $\beta$-gal-positive cells in non-transduced hMSCs at different passages and in transduced hMSCs at passage 20. Upper panels show representative images of SA- $\beta$-gal-positive cells. (c) P53, P21 and P16 mRNA gene expression by Taqman Assays at early $(P \leq 5)$, middle $(P>5-P \leq 10)$ and late $(P \geq 15)$ passages in hMSCs, and passage $>20$ in hTERT-MSCs. (d) Representative images of western blot for $P 53, P 21$ and $P 16$ protein levels of one hMSC sample (FT34hMSC) at early, middle and late passages, and one hTERT-MSC line at passage $>20$. $\beta$-actin was detected as a loading control. All independent hMSC cultures followed the same protein profile expression. All above experiments were performed with four independent hMSC samples and their respective transduced hTERT-MSC counterparts. Data are means \pm S.E.M. $\left({ }^{\star} P<0.050\right)$

We also studied changes in metaphase chromosome number during long-term hMSC culture by DAPI staining. At early passages, nearly $80 \%$ of metaphases had 46 chromosomes, with the exception of the ft36hMSC sample, in which only $46 \%$ of metaphases were diploid (Figure 3c). After several passages, all primary hMSC cultures showed a marked increase in aneuploidy, mostly gain or loss of one or two chromosomes. At passage 14, the percentages of diploid metaphases in the $\mathrm{ft} 34, \mathrm{ft} 36, \mathrm{ft} 40$ and $\mathrm{ft} 43 \mathrm{hMSC}$ samples were, respectively, 18.75, 16.67, 27.27 and 60\% (Figure 3d). In all samples, very few metaphases had fewer than 44 or more than 48 chromosomes (Figure 3d). Late-passage hTERT-MSCs showed a more stable distribution of chromosome number per metaphase. Thereby, ft36- and 
a

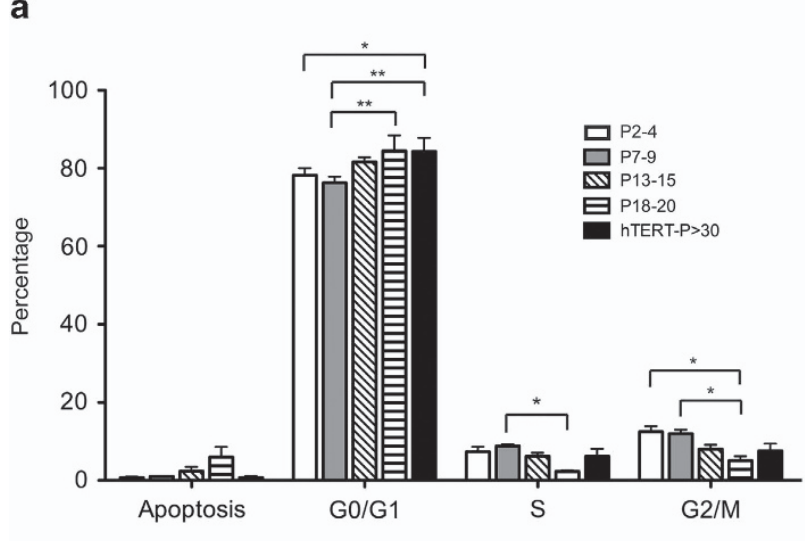

b

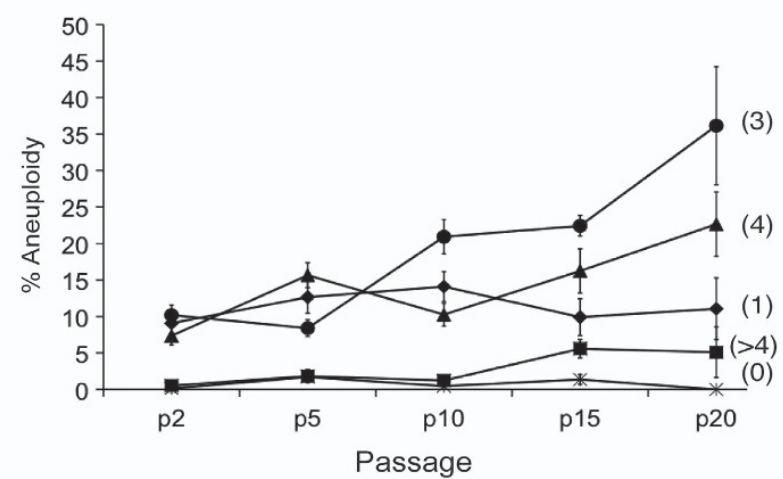

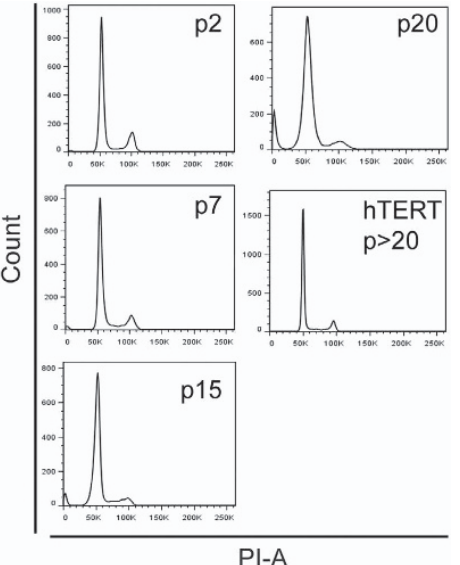

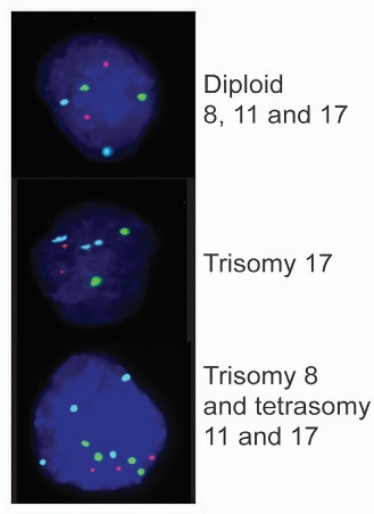

Figure 2 Replicative senescence in hMSCs is associated with aneuploidy. (a) Histogram of DNA content indicating the percentages of cells in apoptosis, G0/G1, S and G2/M phases of the cell cycle. Data were obtained by staining the DNA at various passages in hMSCs and passage $>20$ in hTERT-MSCs. Right panels are representative histograms of one independent hMSC sample and their respective transduced hTERT-MSC counterpart. Note the increase in the coefficient of variation of G0/G1 and G2/M peaks over time in culture in non-transduced cells. Experiment was performed with four independent hMSC samples and their respective transduced hTERT-MSC counterparts. Data are means \pm S.E.M. $\left({ }^{*} P<0.050 ;{ }^{*} P<0.010\right)$. (b) Percentage of aneuploid cells for any of chromosomes 8,11 and 17 classified according to type of aneusomy: (0) nulisomy, (1) monosomy, (3) trisomy, (4) tetrasomy and (>4) polisomy. Right panels show example images of hMSCs hybridized with CEP probes for chromosomes 8 (red), 11 (green) and 17 (light blue). Cultures preferentially accumulated trisomic cells with passages. A total of 100-200 nuclei were analyzed per hMSC culture. Four independent hMSC samples were used for this experiment, and data are means \pm S.E.M.

ft43-TERT-MSC had an essentially diploid set of chromosomes with 84 and $92 \%$ of metaphases with 46 chromosomes (Figure $3 \mathrm{~d}$ ), and ft34- and ft40hTERT-MSC displayed an aneuploid karyotype with 47 chromosomes with a 56 and $72 \%$ of metaphases, respectively, but with a more stable chromosome distribution per metaphase than their non-transduced counterparts at passage 14 (Figure $3 \mathrm{c}$ ). All these results are compatible with the estimates from the interphase analysis.

To identify specific genome copy number variations during long-term culture, we performed a molecular karyotyping by high-throughput a-CGH (array-comparative genomic hybridization) in hMSC and hTERT-MSC cultures at passage 20. Interestingly, the results showed full amplification of chromosome 10 in three independent cultures (ft36hMSC, ft34hTERT-MSC and ft40hTERT-MSC), and an amplification of the 20q chromosomal arm in two independent cultures (ft34hMSC and ft34hTERT-MSC) (Supplementary Figure S2).

The senescence-prone cell subpopulation is highly aneuploid and has a low proliferation rate. The relationship between cell size, morphology and senescence is well known ${ }^{13,20}$ and we have evidenced progressive accumulation with passage of larger and complex cells (estimated by forward and side scatter, respectively); in contrast, all hTERT-MSC cultures maintained a more homogeneous size and complexity throughout the culture (Figure 4a). We selected senescent and non-senescent subpopulations from a heterogeneous hMSC culture at midpassage ( $p 5-7)$. hMSCs were separated by FACS into subpopulation $\beta$, showing a characteristic senescence phenotype, and subpopulation $\alpha$, with non-senescent characteristics (smaller size and less complexity; Figure 4b). Subpopulation $\beta$ was enriched for SA- $\beta$-gal-positive cells $(44.44 \pm 5.90 \%$ versus $14.22 \pm 3.65 \%$ in subpopulation $\alpha$ ) (Figure 4c). Interestingly, interphase FISH analysis showed that $56.48 \pm 4.54 \%$ of subpopulation $\beta$ cells were aneuploid, compared with $26.42 \pm 5.15 \%$ of subpopulation $\alpha$ cells (Figure $4 d$ ). These data indicate that increased cell size and senescence are accompanied by cytogenetic disorders, but that a significant proportion seems to be initiated earlier, when no morphological alterations are detectable. The growth curves of these subpopulations confirmed that the large-cell fraction $(\beta)$ was 
Table 1 Percentage of aneuploid cells in hMSC and hTERT-MSC samples

\begin{tabular}{|c|c|c|c|c|}
\hline \multicolumn{5}{|c|}{$\%$ Aneuploidy per chromosome (hMSC) } \\
\hline Passage 2 & chr 8 & chr 11 & chr 17 & Total \\
\hline Ft34 & 6.70 & 9.28 & 9.79 & 21.13 \\
\hline Ft36 & 10.34 & 11.03 & 13.79 & 21.38 \\
\hline $\mathrm{Ft} 40$ & 7.47 & 7.05 & 12.45 & 19.92 \\
\hline Ft43 & 5.88 & 7.84 & 7.45 & 14.94 \\
\hline Ft35 & 9.94 & 10.53 & 15.20 & 24.56 \\
\hline Mean & 8.07 & 9.15 & 11.74 & 20.39 \\
\hline S.E.M. & 0.89 & 0.76 & 1.39 & 1.56 \\
\hline Passage 5 & chr 8 & chr 11 & chr 17 & Total \\
\hline Ft34 & 8.77 & 14.04 & 17.54 & 26.32 \\
\hline Ft36 & 10.70 & 13.20 & 15.30 & 28.46 \\
\hline $\mathrm{Ft} 40$ & 13.80 & 14.60 & 12.30 & 22.21 \\
\hline Ft43 & 10.20 & 14.30 & 11.60 & 21.77 \\
\hline Ft35 & - & - & - & \\
\hline Mean & 10.87 & 14.04 & 14.19 & 24.69 \\
\hline S.E.M. & 1.06 & 0.30 & 1.38 & 1.62 \\
\hline Passage 10 & chr 8 & chr 11 & chr 17 & Total \\
\hline $\mathrm{Ft34}$ & 13.51 & 14.10 & 16.76 & 32.43 \\
\hline Ft36 & 20.90 & 23.18 & 16.82 & 41.36 \\
\hline Ft40 & 8.88 & 18.93 & 19.53 & 36.69 \\
\hline Ft43 & 10.90 & 14.74 & 9.62 & 25.64 \\
\hline Ft35 & 13.95 & 20.93 & 18.60 & 34.88 \\
\hline Mean & 13.63 & 18.38 & 16.27 & 34.20 \\
\hline S.E.M. & 2.04 & 1.75 & 1.74 & 2.59 \\
\hline Passage 15 & chr 8 & chr 11 & chr 17 & Total \\
\hline Ft34 & 18.78 & 15.15 & 20.00 & 35.15 \\
\hline Ft36 & 17.23 & 20.23 & 17.86 & 40.47 \\
\hline Ft40 & 8.88 & 18.93 & 19.53 & 37.28 \\
\hline $\mathrm{Ft} 43$ & 17.27 & 22.27 & 17.00 & 32.73 \\
\hline Ft35 & - & - & - & \\
\hline Mean & 15.54 & 19.15 & 18.60 & 36.41 \\
\hline S.E.M. & 2.25 & 1.50 & 0.70 & 1.64 \\
\hline Passage 20 & chr 8 & chr 11 & chr 17 & Total \\
\hline Ft34 & 20.00 & 22.96 & 28.89 & 45.19 \\
\hline Ft36 & 26.05 & 29.41 & 30.25 & 50.42 \\
\hline Ft40 & - & - & - & - \\
\hline $\mathrm{Ft43}$ & 17.65 & 17.65 & 32.03 & 44.44 \\
\hline Ft35 & 10.90 & 18.18 & 19.09 & 31.82 \\
\hline Mean & 18.65 & 22.05 & 27.56 & 42.97 \\
\hline S.E.M. & 3.13 & 2.73 & 2.90 & 3.95 \\
\hline
\end{tabular}

\% Aneuploidy per chromosome (hTERT-MSC)

\begin{tabular}{lcccr}
\hline Passage $>20$ & chr 8 & chr 11 & chr 17 & Total \\
\hline Ft34tert & 9.74 & 9.09 & 9.74 & 19.48 \\
Ft36tert & 7.20 & 6.40 & 5.60 & 13.73 \\
Ft40tert & 4.84 & 4.84 & 7.26 & 15.25 \\
Ft43tert & 6.35 & 7.14 & 9.52 & 18.25 \\
& & & & \\
Mean & 7.03 & 6.87 & 8.03 & 16.68 \\
S.E.M. & 1.73 & 1.50 & 0.88 & 1.32
\end{tabular}

Abbreviations: hMSC, human mesenchymal stem cell; hTERT, human telomerase reverse transcriptase.

Percentage (\%) of aneuploid cells for each chromosome (chr8, chr11 and chr17) in four or five independent hMSC samples at passages 2, 5, 10 and 20, and in four derived hTERT-MSC cultures at passage $>20$. The table shows mean \pm S.E.M. aneuploidy per chromosome and the total aneuploidy for the three chromosomes. As more than one chromosome can be affected in the same cell, the percentage of total aneuploidy is not the sum of the percentages of aneuploidy of the three chromosomes.

Interphase nuclei were analyzed by interphase FISH using chromosomespecific centromere probes for chromosomes 8,11 and 17. unable to propagate in culture (Figure 4e), indicating that a high level of aneuploidy in hMSCs is associated with a low proliferative capacity.

hTERT overexpression decreases oxidative stress, modifies metabolism and controls ploidy. We previously reported that aneuploidy is strongly promoted in vitro by oxidative stress. ${ }^{27}$ Given that $h T E R T$ overexpression maintains aneuploidy at basal levels during cell-culture expansion, we tested whether $h T E R T$ influences the oxidative state of hMSCs. hMSC-replicative senescence was accompanied by a progressive increase in total and mitochondrial $\mathrm{O}_{2}^{-}$levels, whereas hTERT-MSCs maintain significantly lower $\mathrm{O}_{2}^{-}$levels (Figure 5a). Quantification of protein oxidation and lipid peroxidation products confirmed that $h T E R T$ overexpression has a pronounced antioxidative effect, reducing carbonyl and malondialdehyde (MDA) generation to one-third of the levels detected at early passages in non-transduced cells (Figure $5 b$ ).

To ascertain whether ROS is a key promoter of aneuploidy, hMSCs and hTERT-MSCs were treated with an inducer agent of $\mathrm{O}_{2}^{-}$(40 $\mu \mathrm{M}$-paraquat for 3 weeks). This treatment strongly promoted aneuploidy of chromosomes 8, 11 and 17 in both the genetic backgrounds, but the effect was more pronounced in hMSCs (Supplementary Figure S3). Interestingly, in hTERT-MSCs, although telomere attrition was effectively inhibited, exogenous ROS increased the generation of aneuploid cells by up to two-fold (Supplementary Figure S3).

Given that mitochondria are the main sources of ROS in hMSCs, we evaluated mitochondrial physiology in hMSC cultures. Analysis of mitochondrial oxygen consumption rate (OCR) showed that the basal OCR in hMSCs increased progressively with passage and that the rate in hTERT-MSCs at late passages was similar to that in early-passage hMSCs (Figure 5c). To evaluate whether the increased oxygen consumption, $\mathrm{O}_{2}^{-}$production and subsequent oxidative damage observed during senescence are related to a dysregulation of mitochondrial biogenesis, we quantified mitochondrial content by Mitotraker green (Figure $5 d$ ) and content of porin, the most abundant protein in the outer mitochondrial membrane (Figure 5e). We additionally quantified levels of the principal protein scavenger of mitochondrial superoxide, MnSOD (SOD2) (Figure 5e). Mitochondrial mass increased slightly with senescence and, interestingly, also with $h T E R T$ overexpression (Figures $5 \mathrm{~d}$ and e). SOD2 was significantly overexpressed in senescent cells and slightly increased in hTERT-MSCs compared with early-passage hMSCs (Figure 5e). These results thus show that senescence significantly alters hMSC metabolism and oxidative status, and that $h T E R T$ overexpression could be a key regulator of metabolic status.

Comparative gene expression profiling of hMSCs reveals dysregulation of ploidy-controlling genes with passages. We profiled microarray gene expression at passages 2 and 21 in four hMSC cultures. In order to be more restrictive, differentially expressed genes were classified by statistical significance and not by fold change, and 42 significantly dysregulated genes ( $q$-value $<5 \%$ ) at passage 21 were found (Supplementary Table S1). Principal 
a
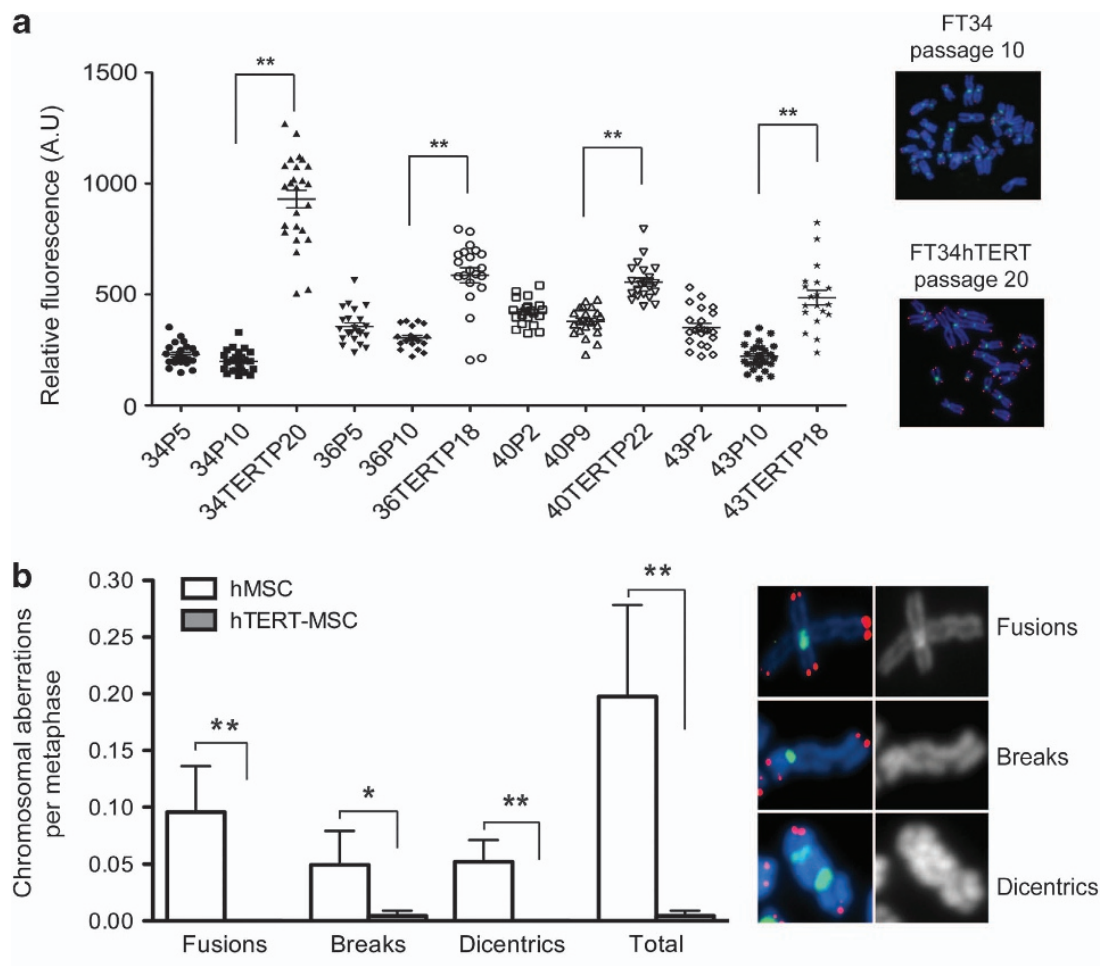

c

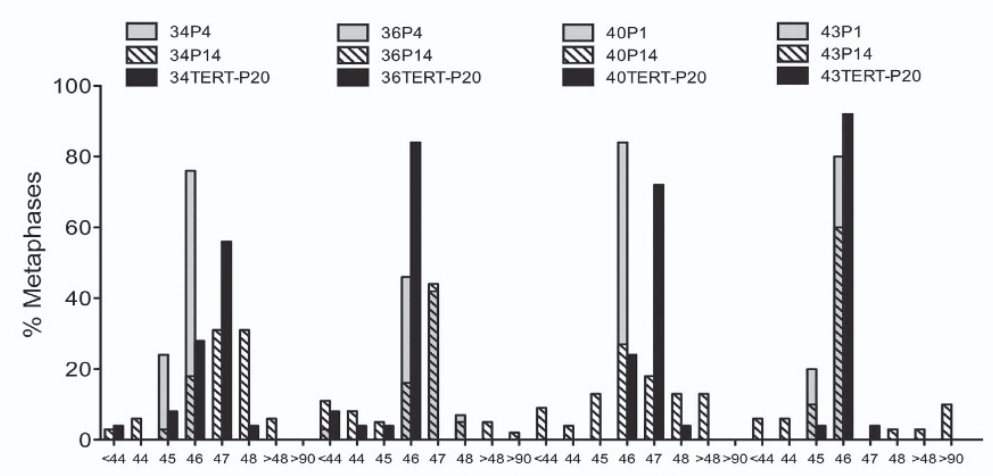

Chromosome number / metaphase

Figure 3 hTERT overexpression in hMSCs elongates telomeres and reduces chromosome abnormalities. (a) Telomere length analysis by Q-FISH in metaphases from four primary hMSC samples at passages $P \leq 5$ and passages $P \geq 10$, and in hTERT-MSCs at passage $P>18$. Upper panels show representative images of metaphases from hMSC and hTERT-MSC cultures, stained with PNA telomere probe (red) and centromere probe (green). (b) Cytogenetic analysis of structural chromosomal aberrations in metaphase cells from hMSC and hTERT-hMSC cultures. Right panels show examples of chromosomal aberrations in cells processed by FISH with centromere probes (green) and telomere PNA probes (red). All above experiments were performed with four independent hMSC samples and their respective transduced hTERT-MSC counterparts. Data are means \pm S.E.M. $\left({ }^{*} P<0.050 ;{ }^{* *} P<0.010\right)$ (c) Chromosome number analysis in metaphase of four hMSCs at passages $P<5$ and passage 14 , and in four hTERT-MSCs at passage 20. Histogram represents the percentage of metaphases with a specific number of chromosomes in four independent hMSC samples and their transduced counterparts

components analysis (PCA) revealed that replicative senescence differentially altered the gene expression pattern of all the hMSC samples, suggesting an important stochastic component during senescence (Supplementary Figure S4), in line with previous reports. ${ }^{36}$

Despite the small number of significantly dysregulated genes identified, gene enrichment analysis (Ingenuity Systems; $q$-value <12\%; 96 genes) identified over 1000 significantly altered functions in 64 categories $(P \leq 0.03)$. These functions include processes essential for cell survival and viability such as proliferation, apoptosis and chemotaxis. Interestingly, 69 processes associated with cancer and cell cycle were significantly altered, with genes related to ploidy being the most significantly over-represented $(P<0.00037)$ (Supplementary Table S2). Eight genes linked to cancer and cell cycle processes were significantly altered ( $q$-value $<12 \%$ ) (Table 2 and Supplementary Table S1), and dysregulation of four of these (SCIN (scinderin), AKAP9 (A kinase (PRKA) anchor protein (yotiao) 9), EDN1 (endothelin 1) and CXCL12 (chemokine (C-X-C motif) ligand 12)) has been associated with increased aneuploidy or transformation. ${ }^{37-41} S C I N$, a $\mathrm{Ca}^{2+}$-dependent filamentous actin-severing protein, has been reported to promote polyploidy and cell enlargement, and to inhibit proliferation of 
a

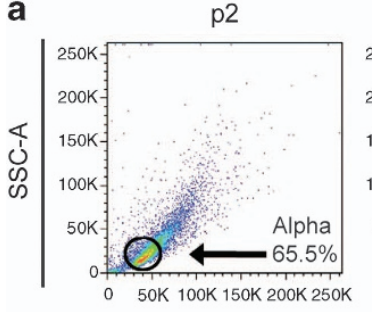

p7

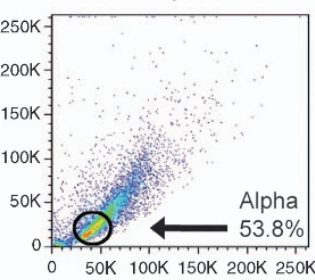

p15

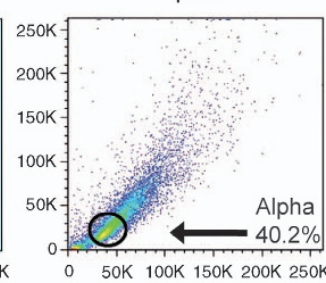

p20

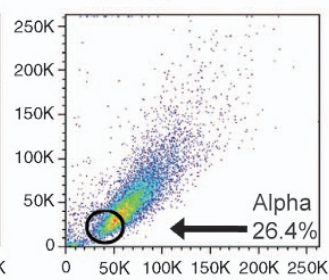

hTERT-p>20

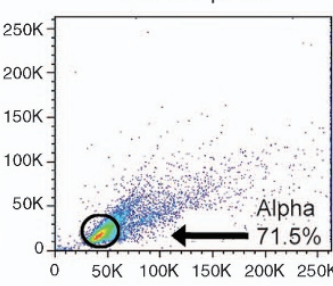

FSC-A

b

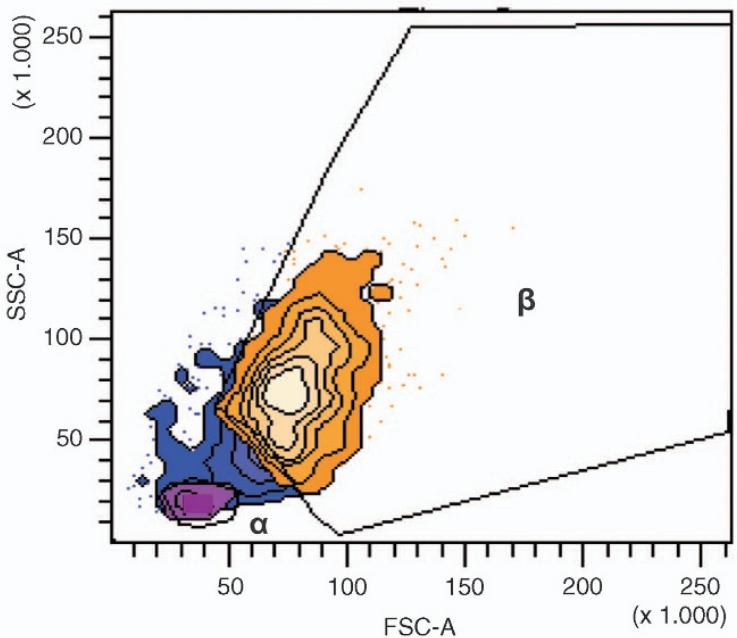

C

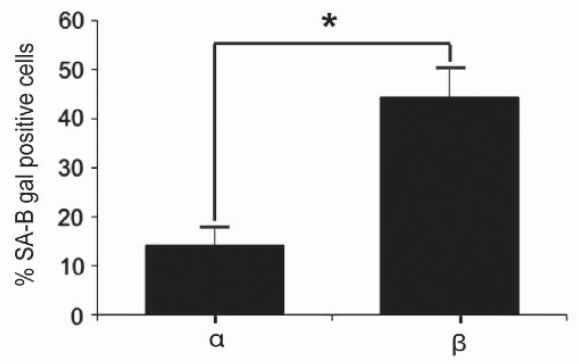

d

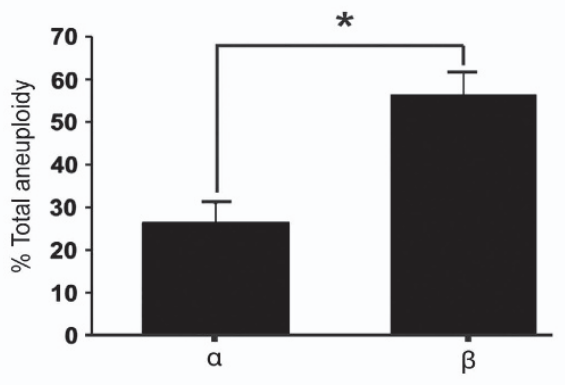

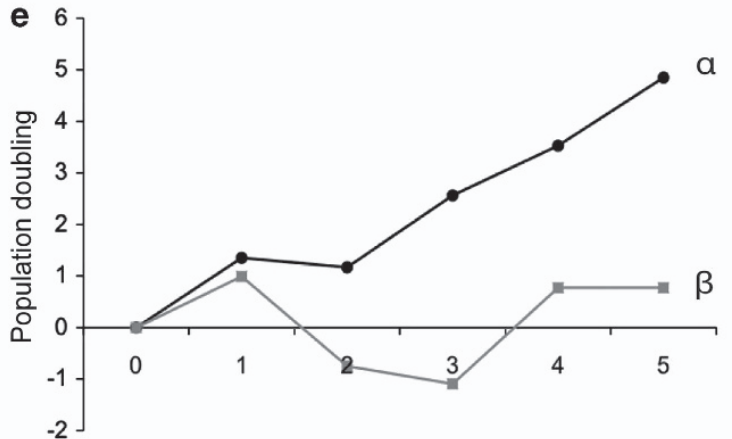

Passage

Figure 4 The senescence-prone cell subpopulation is significantly aneuploid and has reduced proliferation rate. (a) Representative FSC-A/SSC-A plot diagrams at assorted passages in hMSCs and at passage $P>20$ in hTERT-MSCs. Black circles indicate the most common FSC-A/SSC-A subpopulation (alpha) at initial passages. The percentage of the alpha subpopulation is indicated for each passage. The above experiment was performed with four hMSC samples and their respective transduced hTERT-MSC counterparts, and all of them followed the same kinetics. (b) Representative scatter plot from a FACS assay in hMSCs at passages 5-7, separating cells of large size (forward scatter) and high complexity (side scatter) (subpopulation $\beta$ ) from cells of small size and low complexity (subpopulation $\alpha$ ). (c) Percentage of SA- $\beta$-gal-positive hMSCs in subpopulations $\alpha$ and $\beta$ at the third passage after sorting. (d) Percentage of aneuploid cells for any of the chromosomes 8,11 and 17 in subpopulations $\alpha$ and $\beta$ at the third passage after sorting. (e) Growth curves of subpopulations $\alpha$ and $\beta$ over five passages after sorting, revealing impaired proliferation of the more senescent hMSC subpopulation $(\alpha)$. Cell sorter experiments were performed in triplicate with one independent hMSC sample (ft34hMSC). Data are means \pm S.E.M. ( ${ }^{\star} P<0.050$ )

megakaryoblastic leukemia cells. ${ }^{41}$ AKAP9 is a scaffold protein that participates in the signaling machinery in the centrosome. ${ }^{39} E D N 1$, a pro-survival growth factor frequently produced by cancer cells, ${ }^{40}$ has a critical role in colon cancer. ${ }^{37}$ CXCL12 (also called stromal cell-derived factor 1 or SDF-1) has been linked to the polyploidization of hematopoietic cells and their differentiation to the megakaryocyte lineage. ${ }^{38}$

The microarray gene expression results were verified by qRT-PCR analysis of six of these cancer and cell cycle genes:
SCIN, AKAP9, EDN1, CXCL1, CXCL12 and CD70. SCIN, $E D N 1$ and $A K A P 9$ were significantly upregulated at passage 22 compared with passage 2, whereas CXCL1 and CD70 were significantly downregulated $(P<0.05)$ and $C X C L 12$ showed a downward trend (Figure 6a). Examination of the four genes implicated in aneuploidy (SCIN, AKAP9, EDN1 and $C X C L 12$ ) at intermediate passages showed that these mRNA expression changes mostly occur at mid-late passage $(P>12)$ (Supplementary Figure S5A). qRT-PCR analysis of 
a

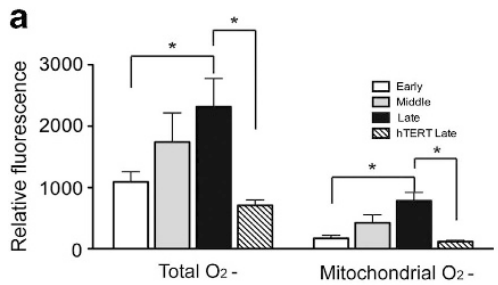

C

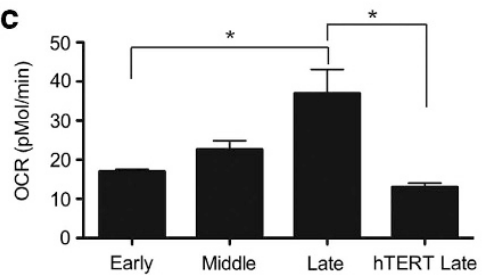

e

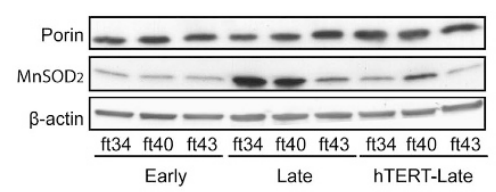

b
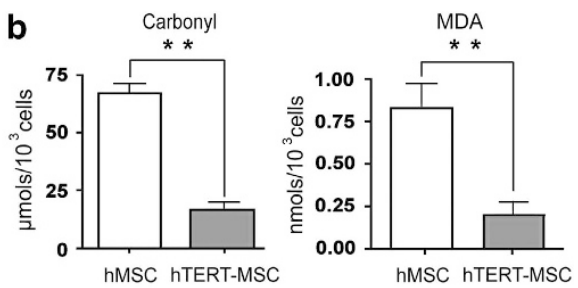

d
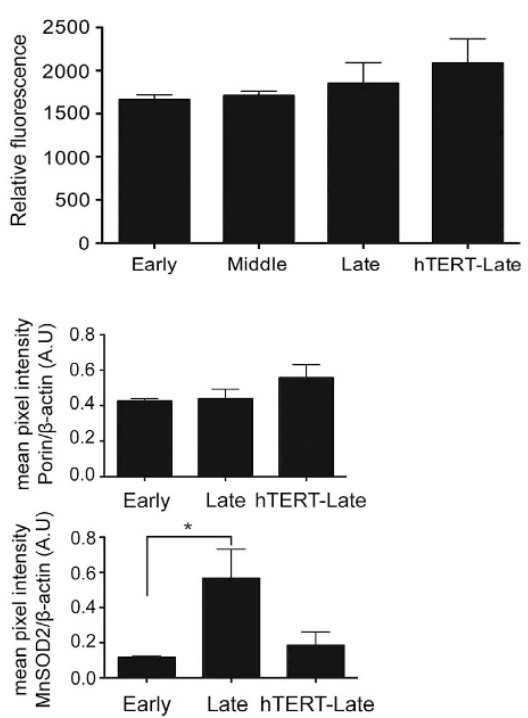

Figure 5 Replicative senescence in hMSCs promotes oxygen consumption and oxidative stress, and is decreased by $h T E R T$ overexpression. (a) Relative levels of total and mitochondrial ROS $\left(\mathrm{O}_{2}^{-}\right)$detected by flow cytometry using DHE (di-hydroethidium) and MitoSox red fluorescence in four hMSC lines at early, middle and late passage, and in derived hTERT-MSC cultures at late passage. (b) Levels of protein carbonyls and MDA in four hMSC samples (white) and derived hTERT-MSC samples (gray) at passage $P=5$ and passage $P>20$, respectively. All above experiments were performed with four independent hMSC samples and their respective transduced hTERT-MSC counterparts. Data are means \pm S.E.M ( $\left.{ }^{*} P<0.050 ;{ }^{*} P<0.010\right)$. (c) Basal oxygen consumption rate (pmoles/min) in hMSCs at early, $16.74 \pm 0.68$; middle, $22.68 \pm 2.24$ and late passages, $36.79 \pm 6.01 \mathrm{pMoles} / \mathrm{min}$, and in hTERT-MSCs at late passage, $13 \pm 0.90 \mathrm{pMoles} / \mathrm{min}$. Seahorse experiment was performed in eight replicates with four hMSC samples and their respective transduced hTERT-MSC counterparts. Data are means \pm S.E.M. $\left({ }^{*} P<0.050 ;{ }^{* \star} P<0.010\right)$. (d) Relative differences of the mitochondrial content in four hMSC and their derived hTERT-MSCs using Mitotracker green staining and quantifying the fluorescence by flow cytometry. (e) Western blot of the mitochondrial protein Porin and the ROS scavenger MnSOD (SOD2) in three hMSC cultures at early and late passages, and their transduced counterparts at late passage. The lower histogram shows protein quantification by pixel density analysis with ImageJ software, normalized to the $\beta$-actin signal. Data are shown as means $\pm S$.E.M. $\left({ }^{*} P<0.050\right.$; $\left.{ }^{* *} P<0.010\right)$

Table 2 Cell cycle and cancer genes identified by Ingenuity Pathway analysis

\begin{tabular}{|c|c|c|c|c|}
\hline Gene symbol & Description & Fold change & LOG fold change & $q$-value (\%) \\
\hline SCIN & Homo sapiens scinderin $(S C I M)$ & 12.31 & 3.62 & 2.95 \\
\hline ACVR1C & Homo sapiens activin A receptor, type IC & 2.94 & 1.56 & 2.95 \\
\hline AKAPG & Homo sapiens $A$ kinase $(P R K A)$ anchor protein (yotiao) 9 & 2.36 & 1.24 & 11.50 \\
\hline$E D N 1$ & Homo sapiens endothelin 1 (EDN1) & 1.89 & 0.92 & 5.03 \\
\hline CXCL2 & Homo sapiens chemokine (C-X-C motif) ligand 2 & 0.19 & -2.39 & 4.61 \\
\hline CXCL12 & $\begin{array}{l}\text { Homo sapiens chemokine (C-X-C motif) ligand } 12 \\
\text { (stromal cell-derived factor } 1 \text { ) }\end{array}$ & 0.14 & -2.86 & 3.69 \\
\hline$C D 70$ & Homo sapiens CD70 molecule (CD70) & 0.10 & -3.36 & 3.69 \\
\hline CXCL1 & Homo sapiens chemokine (C-X-C motif) ligand 1 & 0.09 & -3.45 & 0.00 \\
\hline
\end{tabular}

Genes in the cell cycle and cancer categories identified in the Ingenuity Pathway analysis of the gene expression data as being dysregulated in senescent cultures; $P<0.12(n=4)$

hTERT-MSCs at passage 22 showed that hTERT overexpression prevents culture-associated changes in the expression of these aneuploidy genes (Figure 6b). Dysregulation of these genes thus correlates not only with passage number but also with telomerase expression.

To confirm the putative involvement of this handful of functions in hMSC-replicative senescence, we engineered
hMSCs for overexpression of SCIN (pRRL-SCIN-GFP) or for knockdown of CXCL12 (pLVX-Sh203-GFP) (Supplementary Figure S5B). To avoid negative selection effects, transduced hMSC cultures (60 and $80 \%$ GFP + cells, respectively) were maintained in standard conditions. After 5 weeks in culture, hMSC cultures lacking CXCL12 (Sh203-GFP) showed an approximately two-fold increase in the number of 

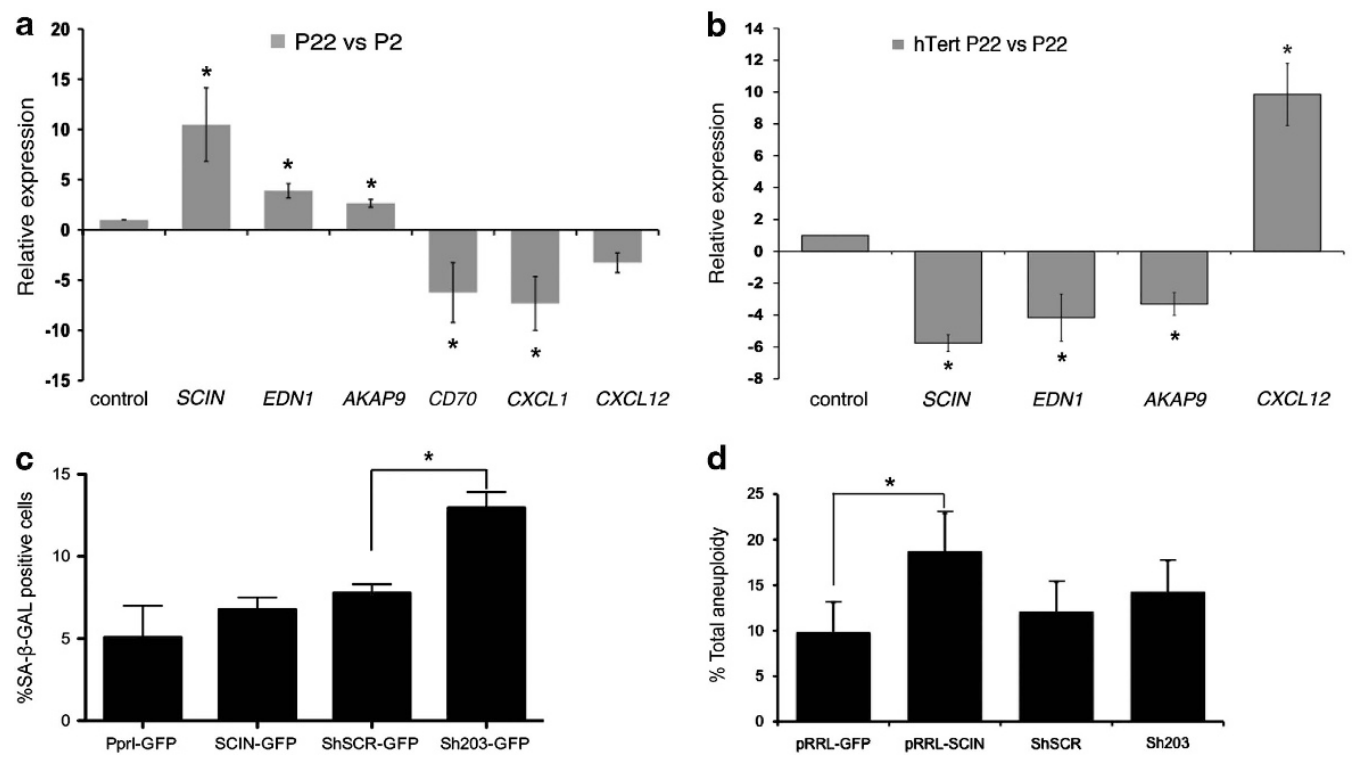

Figure 6 Replicative senescence in hMSCs alters the expression of ploidy-controlling genes. (a) Taqman qRT-PCR quantification of mRNA transcripts for SCIN, EDN1, AKAP9, CD70, CXCL1 and CXCL12 in hMSCs at passage 22 versus passage 2 (control). SCIN, EDN1 and AKAP9 were significantly upregulated at passage 22 compared with passage $2(10.46 \pm 3.65,3.90 \pm 0.72$ and $2.64 \pm 0.39$-fold increases, respectively), whereas $C X C L 1$ and $C D 70$ were significantly downregulated ( $-6.22 \pm 2.99$ and $-7.31 \pm 2.68$, respectively) $(P<0.05)$; and $C X C L 12$ expression was a downward trend $(-3.26 \pm 0.97 ; P=0.09)$. (b) Expression of ploidy-controlling mRNA transcripts in hTERT-MSC cultures versus non-transduced hMSCs (control) at passage 22. hTERT transduction reverses the gene expression phenotype of high-passage hMSCs. The above experiments were performed in triplicate with four independent hMSC and four hTERT-MSC preparations. Data are means \pm S.E.M. ( $\left.{ }^{*} P<0.050\right)$. All above experiments were performed with four independent hMSC samples and their respective transduced hTERT-MSC counterparts. Data are means $\pm S . E . M . ~(n=4)\left({ }^{*} P<0.050\right.$; $\left.{ }^{* \star} P<0.010\right)$. (c) SA- $\beta$-gal-positive cells (\%) at passage 4 in ft40hMSCs transduced with $\mathrm{pRRL}-S C / N$ and pLVX-Sh203 lentiviral vectors or their corresponding controls. Experiments were performed in triplicate for each condition. Data are means \pm S.E.M. $\left({ }^{*} P<0.050\right)$. (d) Aneuploid cells $(\%)$ at passage 4 in ft40hMSCs transduced with pRRL-SCIN and pLVX-Sh203 lentiviral vectors or their corresponding controls. A total of 100-200 nuclei were analyzed per condition. The fraction of aneuploid cells was calculated for each condition, and data were analyzed with Fisher's exact test for two binomials. Data are means \pm S.D. $\left(\chi^{2}\right.$ test $\left.{ }^{*} \chi^{2}>3.84\right)$

SA- $\beta$-GAL-positive cells (Figure 6c). However, in hMSC cultures overexpressing $S C I N$, the trend toward increased senescence was not significant (Figure 6c). Parallel FISH analysis of the level of aneuploidy (chromosomes 8, 11 and 17) in the same cultures revealed that there was no direct correlation with SA- $\beta$-GAL expression: overexpression of $S C I N$ provoked a $>1.5$-fold increase in aneuploidy, whereas aneuploidy in CXCL12-knocked down cells was merely $\sim 1$.1fold that in controls (Figure $6 \mathrm{~d}$ ). These results suggest that upregulation of SCIN might be involved in the generation of aneuploidy, whereas downregulation of $C X C L 12$ would favor the development of SA- $\beta$-GAL-positive cells.

\section{Discussion}

The accumulation of chromosomal abnormalities by diploid human cells when cultured under standard conditions was first reported nearly 50 years ago. ${ }^{42}$ Since then, evidence has accumulated, indicating that genetic instability in human cell cultures is a frequent phenomenon; ${ }^{26-30,43,44}$ indeed, a recent large-scale analysis showed that cultures of pluripotent and multipotent stem cells develop large numbers of cytogenetic aberrations. ${ }^{28}$ Most cell types can therefore be expected to acquire chromosomal aberrations during expansion in culture.

Our results show that expansion of adult adipose-tissuederived hMSCs under standard culture conditions induces aneuploidy, producing mostly trisomic or tetrasomic cells for the affected chromosomes. These atypical cells are present in low percentage at early passage and become more frequent with passage, paralleling the appearance of senescent cells. ${ }^{12}$ Metaphase analysis after several passages revealed frequent gain or loss of one or two chromosomes to generate near-diploid aneuploidy. This is in line with cell cycle analysis that showed a clear increase of the coefficient of variation of G0/G1 and G2/M peaks and an absence of polyploid cells ( $>4 \mathrm{~N}$ ). Surprisingly, microarray-based comparative genomic hybridization $(\mathrm{aCGH})$ revealed that recurrent chromosomal amplifications (whole chromosome 10 and 20q-arm) might be selected during culture, but without overcoming senescence, in agreement with previous reports. ${ }^{31-34}$

No spontaneous immortalization indicate that most aneuploid cells are arrested or quiescent, an interpretation supported by our FACS-based analysis, which demonstrated that most cells of the hMSC subpopulation of enlarged and complex cells ( $\beta$, phenotypically more senescent) were strongly aneuploid and essentially unable to progress in vitro. The progressive accumulation of these aneuploid cells could be due to a more frequent generation of aneuploidy as the culture advances or by aneuploidy-promoting apoptosis resistance, a capacity that has been linked to senescence. $^{45}$

Our results show that forced expression of the telomerase catalytic subunit ( $h T E R T$ ) not only prevents culture senescence, but also significantly increases genetic stability: elongating the telomeres, preventing the accumulation of aneuploid cells (chromosomes 8, 11 and 17), reducing 
variability of chromosome number per metaphase and decreasing the coefficient of variation in peaks of DNA content. Although two hTERT-MSC samples did show recurrent chromosomal amplifications, we suggest that these genetic alterations probably already existed before lentiviral transduction, and subsequently accumulated with further cell culture.

We found that exogenous ROS is able to promote aneuploidy in hMSCs and hTERT-MSCs despite full telomere protection; in addition, hTERT-MSCs have lower levels of oxidative stress than primary hMSCs. These data suggest that hTERT overexpression protects against chromosomal instability also by directly decreasing oxidative stress. In line with this hypothesis, hTERT overexpression decreased oxidative stress by controlling mitochondrial physiology, maintaining a low OCR and limiting dysregulation of antioxidant defenses such as MnSOD. These data are supported by emerging evidence for non-canonical actions of $h T E R T$, which has been demonstrated to act as a transcriptional modulator, and also to alter metabolism and ROS production. ${ }^{46-50}$

The gene expression data reveal that hMSC expansion culture is associated with significantly altered expression of genes associated with ploidy regulation ( $S C I N, A K A P 9, E D N 1$ and $C X C L 12$ ), reinforcing the results of interphase FISH analysis showing progressive accumulation of aneuploid cells during senescence. Importantly, overexpression of $h T E R T$ prevented the dysregulation of these ploidy-controlling genes, in agreement with the maintenance of basal levels of aneuploidy. Attempts to demonstrate the direct involvement of some of the identified functions in senescence and chromosome instability, by gain-of-function or downregulation using lentiviral vectors, suggest that $S C I N$ upregulation might be involved in the generation of aneuploidy, and that $C X C L 12$ downregulation could favor the development of SA- $\beta$-GALpositive cells. Senescence is likely to be a highly multifactorial process with a marked stochastic contribution, and these results therefore suggest that the whole process might require concerted action of several of the identified functions.

It is important to highlight that compelling evidence suggests that senescence in different human primary cells is associated with secretory phenotypes (SASP) that significantly increase the secretion of several proinflammatory chemoquines and cytoquines. ${ }^{51,52}$ Our microarray gene expression analysis indicates that three main chemoquines are significantly downregulated during hMSC senescence: CXCL1, CXCL2 and CXCL12. However, in parallel studies, we have confirmed that senescent hMSCs show the typical generalized increase of the secretion of proinflammatory cytoquines and chemoquines, including CXCL1 (Sepúlveda et al., submitted). We cannot provide a definitive explanation for this discrepancy, but differences between mRNA gene expression and the protein levels of secretome could be expected, as well as specific variations between cell lineages, as have been previously observed. ${ }^{53}$

Our results indicate that replicative senescence in hMSCs is intimately associated with the development of aneuploidy. Generation of aneuploid hMSCs appears to be an unavoidable effect of prolonged ex vivo culture, probably as a consequence of the non-physiological proliferation context. This aneuploidy might be induced in a multifactorial manner by oxidative stress, telomere shortening and altered expression of ploidy-controlling genes. hTERT overexpression effectively controls genetic stability and prevents senescence in hMSCs, both by maintaining telomere length, and by reducing oxidative stress and controlling dysregulation of aneuploidy related genes. We propose that the identified genes, together with an estimate of aneuploidy, could be used as biomarkers of senescence in stem-cell preparations.

\section{Materials and methods}

Cell and culture conditions. Five independent human mesenchymal stem-cell lines isolated from adipose tissue were obtained from Inbiobank Stem Cell Bank (www.inbiobank.org). These cells have a typical hMSC phenotype: $\mathrm{CD} 29+, \mathrm{CD} 73+(\mathrm{SH} 3$ and SH4), CD105 + (SH2), CD166 +, CD45 - and CD31 - . All cells were processed by Inbiobank, following procedures based on ISO9001:2000 for good manufacturing practice. hMSC were cultured $\left(2 \times 10^{3}\right.$ cells $\left./ \mathrm{cm}^{2}\right)$ under standard cell-culture conditions in high-glucose $(4.5 \mathrm{mg} / \mathrm{ml})$ Dulbecco's Modified Eagle's Medium (DMEM, Sigma-Aldrich, Saint Louis, MO, USA) supplemented with $10 \%$ fetal bovine serum (FBS, Sigma-Aldrich), $2 \mathrm{mM}$ glutamine, $100 \mathrm{U} / \mathrm{ml}$ penicillin and $1000 \mathrm{U} / \mathrm{ml}$ streptomycin at $20 \% \mathrm{O}_{2}$. Medium was changed twice a week and cells were passaged once every 7 days. For exposure to exogenous ROS, subconfluent $(70 \%)$ cultures were exposed to $40 \mu \mathrm{M}$ $\mathrm{PQ}$ (Sigma-Aldrich) every 3 days for 3 weeks. Long-term cell growth in vitro was monitored by counting cell number with a hemocytometer. Cumulative PD was calculated with the formula PDL $=(\log (\mathrm{Nn} / \mathrm{Nn}-1)) / \log 2$ (n: passage; $\mathrm{N}$ : cell number). DNA fingerprinting with nine single-nucleotide polymorphisms at early (p2) and late (p20) passages was peformed in all hMSC cultures and no evidence of cross-contamination was detected.

Lentiviral transduction. Four primary hMSCs at passage 5 were transduced with lentiviral vector (pRRL.SIN18) encoding the human telomerase reverse transcriptase catalytic subunit ( $h T E R T$ ), as described. ${ }^{54}$ Telomerase expression was monitored by TaqMan gene expression assay and confirmed by TRAP activity assay. Overexpression of SCIN and downregulation of CXCL12 were performed by lentiviral transduction of one hMSC sample (ft40) at passage 2 with pRRL-SCIN-GFP and pLVX-ShRNA-GFP (203) vectors, respectively. pRRLGFP empty and pLVX-ShSCR-GFP were used as negative controls. Transduction was confirmed by TaqMan gene expression assay.

Aneuploidy analysis (FISH). Cells were incubated with $10 \mu \mathrm{g} / \mathrm{ml}$ colcemid for $4 \mathrm{~h}$ at $37^{\circ} \mathrm{C}$, treated with $0.075 \mathrm{M} \mathrm{KCl}$ for $15 \mathrm{~min}$ at $37^{\circ} \mathrm{C}$ and fixed three times in methanol/acetic acid $(3: 1)$ at $4{ }^{\circ} \mathrm{C}$. Cell suspensions were dropped onto clean slides and air dried for $24 \mathrm{~h}$. CEP probes for chromosomes 8, 11 and 17 from the Breast Aneusomy Multi-Color Probe kit (Abbot, Des Plaines, IL, USA) were applied to the cells according to the manufacturer's instructions. At least 100 cells per cell line were analyzed for each passage analyzed (2, 5, 10, 15 and 20). For chromosome analysis in metaphase, cell suspensions enriched in metaphases were dropped onto clean wet slides, aged overnight and stained with DAPI (4,6 diamidino-2-phenylindole) in Vectashield $\mathrm{H}-1200$ mounting medium (Vector Laboratories, Burlingame, CA, USA). Chromosome counts were performed on at least 100 nucleuses per cell line. Fluorescence images were acquired with a Nikon $90 i^{28}$ microscope (Nikon Instruments, Melville, NY, USA) fitted with a $\times 100$ planfluor 1.3N/A objective, appropriate filters and an $\mathrm{Hg}$ Intensilight fluorescence unit. Digital images were acquired with a JAI monochrome CCD cooled camera (Kushima City, Japan) linked to Cytovision Genus software (Genetix, Boston, MA, USA).

Chromosome number and chromosomal aberrations. FISH was carried out as described above. Chromosomes were counted and structural chromosomal aberrations detected by superimposing telomere and centromere images on the DAPI-stained chromosomes in ImageJ (Bethesda, MD, USA). At least 25 metaphases of each cell line and condition were analyzed $(n=4)$. Chromosomal aberrations were identified as follows: chromatid or chromosomal breakages: gaps in one or two chromatids whose corresponding centromere was identified; chromosomal fusions: two chromosomes joined without telomere signals at the fusion point with one centromeric signal; dicentrics: chromosomal fusions between two chromosomes joined without telomere signals at the fusion point with 
two centromeric signals. The percentage of each type of aberration in each cell line and condition was used for statistical analysis.

Western blot analysis. Cells were lysed in SDS Ripa lysis buffer $(50 \mathrm{mM}$ Tris- $\mathrm{HCl}, \mathrm{pH} 7.4,1 \% \mathrm{NP} 40,0.25 \%$ sodium deoxycholate, $150 \mathrm{Mm} \mathrm{NaCl}, 1 \mathrm{mM}$ EDTA) containing proteinase inhibitor complex (mini-complete, Roche, Basel, Switzerland). Proteins were electrophoresed on $12.5 \%$ SDS-PAGE gels (Invitrogen, Carlsbad, CA, USA) and transferred to nitrocellulose membranes. Membranes were sequentially incubated with 1:500 dilutions of mouse anti-P53 (Pab240, Santa cruz Biotech, Santa Cruz, CA, USA), anti-P21 (F5, Santa cruz Biotech), anti-Porin (A31855, Invitrogen), rabbit anti-P16 (M-156, Santa cruz Biotech), anti-MnSOD (06-984, Millipore, Billerica, MA, USA) and mouse anti- $\beta$-actin (Abcam 8226, Cambridge, MA, USA) as a loading control. Stained proteins were detected with the Amersham ECL Advance Western Blotting Detection Kit (GE Healthcare Life Sciences, Buckinghamshire, UK), and films were scanned and quantified with ImageJ.

Senescence-associated $\beta$-galactosidase activity assay. The assay is based on histochemical staining for $\beta$-galactosidase activity at $\mathrm{pH} 6$. Unmodified and hTERT-transduced hMSCs were plated $\left(2 \times 10^{3} \mathrm{cell} / \mathrm{cm}^{2}\right)$ in six-well plates at the required passage. After 7 days, the cells were washed with PBS and fixed for $15 \mathrm{~min}$ with the fixing mix solution from the histochemical staining kit (Sigma-Aldrich). Senescent cells were stained by adding $1 \mathrm{ml}$ of the staining mix to each well. Plates were incubated at $37^{\circ} \mathrm{C}$ without $\mathrm{CO}_{2}$, and hMSCs were examined after $16 \mathrm{~h}$

Q-TRAP assay. Telomerase assays were performed on $5000 \mathrm{hMSCs}$ as described ${ }^{55}$ with the following modifications. Proteins were extracted in NP40 lysis buffer (10 mM Tris- $\mathrm{HCl}, 1 \mathrm{mM} \mathrm{MgCl}$, $1 \mathrm{mM}$ EDTA, $1 \% \mathrm{NP} 40,0.25 \mathrm{mM}$ sodium deoxycholate, $10 \%$ glycerol, $150 \mathrm{mM} \mathrm{NaCl}, 5 \mathrm{mM} \beta$-mercaptoethanol (all from Sigma-Aldrich) and $1 \times$ protease inhibitor (Roche) at $\mathrm{pH}$ 8.0. Protein concentration was measured with the DC Protein Assay Kit (Bio-Rad, Hercules, $\mathrm{CA}, \mathrm{USA})$. Extracts (5 and $1 \mu \mathrm{g}$ protein per sample) were incubated with telomerase extension buffer $(500 \mathrm{mM}$ Tris- $\mathrm{AcH}, 500 \mathrm{Mm}$ potassium acetate $30 \mathrm{mM} \mathrm{MgCl}_{2}, 10 \mathrm{mM}$ spermin, $10 \mathrm{mM}$ EGTA, $50 \mathrm{mM} \beta$-mercaptoethanol, $2 \mathrm{mM}$ dAGT; all from Sigma-Aldrich) and $1 \mathrm{mM}$ Oligo TS (5'-AATCCGTCGAGCA GAGTT-3'). Extension reaction of telomerase $(2 \mu \mathrm{l})$ was added to $23 \mu \mathrm{l} \mathrm{PCR}$ reaction mix containing $1 \times$ Power SYBR Green PCR Master Mix, $5 \mathrm{mM}$ EGTA, $2 \mathrm{ng} / \mu \mathrm{l}$ Oligo TS and $4 \mathrm{ng} / \mu \mathrm{l}$ Oligo ACX (5'-GCGCGGC(TTACCC)4-3'). PCR was carried out at $94{ }^{\circ} \mathrm{C}$ for $10 \mathrm{~min}$, followed by 40 cycles of $94^{\circ} \mathrm{C}$ for $15 \mathrm{~s}$ and $60^{\circ} \mathrm{C}$ for $1 \mathrm{~min}$. PCR products were monitored with an ABI PRISM 7700 sequence detection apparatus (Applied Biosystems, Foster City, CA, USA) and analyzed with SDS v2.3 software (Applied Biosystems).

Cell cycle analysis. Cell cycle distribution was examined by propidium iodide (PI) staining. Single suspensions of each hMSC line at assorted passages and of the hTERT-MSC lines at passage $>30$ were obtained. Cells were carefully fixed drop-by-drop in $70 \%$ ethanol and stored at $-20^{\circ} \mathrm{C}$. Samples were washed in PBS, treated for $45 \mathrm{~min}$ with $0.1 \mathrm{mg} / \mathrm{ml}$ RNase A (Sigma-Aldrich) at $37^{\circ} \mathrm{C}$ and stained with $40 \mu \mathrm{g} / \mathrm{ml} \mathrm{PI}$ in PBS for $5 \mathrm{~min}$. Fluorescence intensity was analyzed in a Becton-Dickinson LSR cytometer (BD Biosciences, San Jose, CA, USA). Aggregated cells were excluded by 'doublet discrimination': cells were faced in Side Scatter Channel SSC-H versus SSC-W, and in Forward Scatter Channel FSC-H versus FSC-W, and the subpopulation with equal pulse width was selected. Data were analyzed with FlowJo Cytometry analysis software (Tree Star, Ashland, OR, USA)

Flow cytometry analysis of ROS. Early-passage (p5) hMSC cultures and late-passage $(P>15)$ hTERT-MSC cultures were washed in PBS, trypsinized and resuspended in $\mathrm{HBSS} / \mathrm{Ca} / \mathrm{Mg}$ phenol-red-free medium (Sigma-Aldrich) at $1 \times 10^{6} \mathrm{cells} / \mathrm{ml}$. Samples were incubated at $37^{\circ} \mathrm{C}$ in the dark with $5 \mu \mathrm{M}$ dihydroethidium (DHE) for $30 \mathrm{~min}$ or with $1 \mu \mathrm{M}$ MitoSox Red probe for $10 \mathrm{~min}$ (both probes from Molecular Probes, Invitrogen). DHE and MitoSox Red are specific biomarkers of total and mitochondrial superoxide anion $\left(\mathrm{O}_{2}^{-}\right)$, respectively. After incubation, cells were washed twice in cold PBS to eliminate excess staining solution. Dead cells were excluded by incubation for 5 min with TO-PRO in HBSS/ $\mathrm{Ca} / \mathrm{Mg}$ phenol-red-free medium. $\mathrm{ROS}\left(\mathrm{O}_{2}^{-}\right)$were detected by flow cytometry in a Becton-Dickinson LSR cytometer (BD Biosciences) in channel FL2. The autofluorescence in each sample was subtracted. Aggregated cells were excluded by 'doublet discrimination' in the same way as in cell cycle analysis.
Flow cytometry analysis of mitochondrial content by Mitotracker green staining. Early-passage (p5) hMSC and late-passage $(P>18)$ hTERT-MSC cultures were washed in PBS, trypsinized and incubated at $1 \times 10^{6} \mathrm{cell} / \mathrm{ml}$ in HBSS$/ \mathrm{Ca} / \mathrm{Mg}$ phenol-red-free medium (Sigma-Aldrich) containing $100 \mathrm{nM}$ Mitotraker green (Molecular Probes, Invitrogen) for $30 \mathrm{~min}$ in the dark. Dead cells were excluded by incubation for 5 min with TO-PRO in HBSS/Ca/Mg phenol-red-free medium. Fluorescent signal was detected by flow cytometry in a Becton-Dickinson LSR cytometer (BD Biosciences) in channel FL1, and data were analyzed with Summit v4.3 software (Dako Inc., Carpinteria, CA, USA).

\section{Microarray gene expression profiling}

Sample labeling and microarray hybridization: The One-Color Microarray-Based Gene Expression Analysis Protocol (Agilent Technologies, Palo Alto, CA, USA) was used to amplify and label RNA. Briefly, $400 \mathrm{ng}$ of total RNA was reverse transcribed using T7 promoter Primer and MMLV-RT. CDNA was then converted to aRNA using T7 RNA polymerase, which simultaneously amplifies target material and incorporates cyanine 3-labeled CTP. Cy3-labeled aRNA $(1.65 \mu \mathrm{g})$ was hybridized to a Whole Human Genome Microarray $4 \times 44 \mathrm{~K}$ (G4112F, Agilent Technologies) for $17 \mathrm{~h}$ at $65^{\circ} \mathrm{C}$ in $1 \times$ GEx Hybridization Buffer HI-RPM in a hybridization oven (G2545A, Agilent Technologies) set to 10 r.p.m. Arrays were washed according to the manufacturer's instructions, dried by centrifugation and scanned at $5 \mathrm{~mm}$ resolution on an Agilent DNA Microarray Scanner (G2565BA, Agilent Technologies) with the default settings for $4 \times 44 \mathrm{~K}$ format one-color arrays. Scanned images were analyzed with Feature Extraction software (Agilent Technologies).

Data analysis: Feature Extraction data files were imported into GeneSpring GX version 9.0. (Agilent Technologies). Quantile normalization was performed and expression values (log2 transformed) were obtained for each probe. Probes were also flagged (Present, Marginal, Absent) using GeneSpring default settings. Probes with signal values above the lower percentile $\left(20^{\text {th }}\right)$, and flagged as present or marginal in all replicates in at least one of the two conditions under study, were selected for further analysis (23716 probes). Statistical analysis of differential gene expression between passages 21 and 2 was assessed by twoclass paired SAM. PCA was performed with the Gene Spring 12.1 program analysis (Agilent Technologies). Data were deposited in the National Center for Biotechnology Information (NCBI) Gene Expression Omnibus (GEO) (http://www.ncbi.nlm.nih.gov/geo; accession no.: GSE39250).

Ingenuity Pathway analysis: Ingenuity Pathway Analysis software (Ingenuity Systems, www.ingenuity.com) was used to generate an interaction network for genes of interest and for functional enrichment analysis of specific gene data sets. Given the low number of significantly differentially regulated genes obtained (42 genes), Ingenuity Pathway analysis was run with a $q$-value $<12 \%$ (96 genes).

TaqMan assays. hMSC RNA was extracted with TRIzol by standard methods, and the RT reaction was carried out with the SuperScript III Reverse Transcriptase kit (Invitrogen). A total of $10 \mathrm{ng}$ of cDNA per reaction was added to $10 \mu \mathrm{l}$ of $2 \times$ PCR Master Mix (Applied Biosystems). TaqMan Gene Expression Assays (Applied Biosystems) were used for all mRNA quantifications. The PCR was loaded in an ABI PRISM 7700 apparatus and quantified using 7900HT v2.3 software (Applied Biosystems).

Microarray-based comparative genomic hybridization (aCGH). DNA was isolated from hMSC and hTERT-MSCs at passage 20 using DNAzol (Invitrogen) according to the manufacturer's instructions. DNA $(1.1 \mu \mathrm{g})$ was first digested with Alul and Rsal $\left(2 \mathrm{~h}\right.$ at $\left.37^{\circ} \mathrm{C}\right)$. Enzymes were inactivated by incubation at $65{ }^{\circ} \mathrm{C}$ for $20 \mathrm{~min}$. Random primers $(5 \mu \mathrm{l})$ were added to the samples, which were incubated for $3 \mathrm{~min}$ at $95^{\circ} \mathrm{C}$ and then for $5 \mathrm{~min}$ on ice. Samples are labeled using Exo-Klenow, dNTPs and cyanine 3-dUTP (C) or cyanine 5-dUTP (M). Samples are incubated for $2 \mathrm{~h}$ at $37^{\circ} \mathrm{C}$, followed by enzyme inactivation at $65^{\circ} \mathrm{C}$ for $10 \mathrm{~min}$. Labeled DNA was purified using Microcon YM-30 filters (Millipore). Cy3- and Cy5-labeled DNAs are mixed and hybridized to the Sure Print G3 Mouse CGH Microarray $(4 \times 180 \mathrm{~K})$ for $24 \mathrm{~h}$ at $65^{\circ} \mathrm{C}$ in $1 \times$ Hi-RPM hybridization buffer (Agilent Technologies), $1 \times$ GE blocking agent (Agilent Technologies) and mouse Cot-1 DNA $(45 \mu \mathrm{g} / \mathrm{ml})$. Arrays were washed and dried according to the manufacturer's instructions (Oligonucleotide Array-Based CGH for Genomic DNA Analysis; Agilent Technologies). Arrays were scanned at $3 \mu \mathrm{m}$ resolution on 
an Agilent DNA Microarray Scanner (G2565BA, Agilent Technologies) using the default settings for $4 \times 44 \mathrm{k}$ format $\mathrm{CGH}$ arrays. Images provided by the scanner were analyzed using Feature Extraction software v10.7 (Agilent Technologies).

OCR measurement. The XF96 Flux analyzer and Prep Station (Seahorse Bioscience XF96 Instrument, Billerica, MA, USA) were used according to the manufacturer's instructions. Briefly, hMSCs were seeded in XF96 cell-culture plates at 2500 cells per well at $20 \% \mathrm{O}_{2}$ or $3 \% \mathrm{O}_{2}$, and cultured for $48 \mathrm{~h}$. The XF96 sensor cartridges were hydrated overnight with $200 \mu \mathrm{l}$ of Seahorse Bioscience XF96 Calibrant at pH 7.4 and stored at $37^{\circ} \mathrm{C}$ without $\mathrm{CO}_{2}$ for $24 \mathrm{~h}$. The culture medium was replaced with serum-free high-glucose DMEM supplemented with glutamine and pen/strep and lacking bicarbonate $(\mathrm{pH}$ 7.4). Cells were then incubated for $15 \mathrm{~min}$ at $37^{\circ} \mathrm{C}$ without $\mathrm{CO}_{2}$ and measurements were performed. Drugs ( $1 \mu \mathrm{M}$ oligomicin and $130 \mu \mathrm{M}$ 2,4-Dinitrophenol) were added according to the supplier's technical specifications.

Detection of protein carbonyls and MDA. Carbonyl derivatives in hMSCs were measured by an adaptation of the method of Levine et $a l^{56}$ Cell suspensions were mixed with $30 \%(\mathrm{v} / \mathrm{v})$ trichloroacetic acid. Protein precipitates were resuspended in $10 \mathrm{mM}$ 2,4-dinitrophenylhydrazine (DNPH) and incubated for $60 \mathrm{~min}$ at $37^{\circ} \mathrm{C}$. Samples were then precipitated with $20 \%$ trichloroacetic acid (v/v) and centrifuged for $10 \mathrm{~min}$ at $1000 \times \mathrm{g}$ at $4{ }^{\circ} \mathrm{C}$. The precipitate was washed twice with ethanol-ethyl acetate $(50 \% \mathrm{v} / \mathrm{v})$ to remove free $\mathrm{DNPH}$, and resuspended in $6 \mathrm{M}$ guanidine, $2 \mathrm{mM}$ phosphate buffer at $\mathrm{pH}$ 2.3. Samples were incubated for $40 \mathrm{~min}$ at $37^{\circ} \mathrm{C}$ and centrifuged for $5 \mathrm{~min}$ at $3000 \times g$ at $4^{\circ} \mathrm{C}$. Absorbance at $360 \mathrm{~nm}$ was measured in supernatents. The levels of protein carbonyls, expressed as $\mu \mathrm{mol} / 10^{3}$ cells, were calculated from the absorbance of supernatents at $360 \mathrm{~nm}$. MDA was detected by HPLC as described by Wong SHY et al., ${ }^{57}$ and results are expressed as nmol/ $10^{3}$ cells.

\section{Conflict of Interest}

The authors declare no conflict of interest.

Acknowledgements. We are indebted to Dr. Judith Campisi (Buck Institute for Age Research) for providing the telomere length control cells and the hTERT lentiviral vector, Marta Ramón (CNIC) for secretarial assistance and Simon Bartlett (CNIC) for English editing. We are also very grateful to Juan Carlos Sepulveda, María Tomé and Manuel A. Gonzalez for providing us essential information in relation with SASP analysis. This work was supported by grants to $A B$ from the Ministry of Science and Innovation (SAF 2008-02099; PLE2009-0147 and PSE010000-2009-3), the Comunidad Autónoma de Madrid (P-BIO-0306-2006) and the Red de Terapia Celular del Instituto de Salud Carlos III (TerCel); to ES from the Fundación Mutua Madrileña, the Ministry of Education (Ramon y Cajal program), the Ministry of Health (FIS PI071023); and to ER from Instituto de Salud Carlos III-FEDER (PS09/01093) and Fundacion Salud 2000-Merck Serono. JCE is a predoctoral fellow funded by TerCel. The CNIC is supported by the Ministry of Economy and Competitiveness and the Pro-CNIC Foundation.

1. Salem HK, Thiemermann C. Mesenchymal stromal cells: current understanding and clinical status. Stem Cells 2010; 28: 585-596.

2. Le Blanc K, Mougiakakos D. Multipotent mesenchymal stromal cells and the innate immune system. Nat Rev Immunol 2012; 12: 383-396.

3. Sotiropoulou PA, Perez SA, Salagianni M, Baxevanis CN, Papamichail M. Characterization of the optimal culture conditions for clinical scale production of human mesenchymal stem cells. Stem Cells 2006; 24: 462-471.

4. Duggal S, Brinchmann JE. Importance of serum source for the in vitro replicative senescence of human bone marrow derived mesenchymal stem cells. J Cell Physiol 2011 226: 2908-2915.

5. Wagner W, Horn P, Castoldi M, Diehlmann A, Bork S, Saffrich R et al. Replicative senescence of mesenchymal stem cells: a continuous and organized process. PLoS One 2008; 3: e2213.

6. Wagner W, Bork S, Horn P, Krunic D, Walenda T, Diehlmann A et al. Aging and replicative senescence have related effects on human stem and progenitor cells. PLoS One 2009; 4: e5846.

7. Hayflick L, Moorhead PS. The serial cultivation of human diploid cell strains. Exp Cell Res 1961; 25: 585-621.

8. Collado M, Blasco MA, Serrano M. Cellular senescence in cancer and aging. Cell 2007; 130: 223-233.

9. Toussaint O, Weemaels G, Debacq-Chainiaux F, Scharffetter-Kochanek K, Wlaschek M Artefactual effects of oxygen on cell culture models of cellular senescence and stem cell biology. J Cell Physiol 2011; 226: 315-321.
10. Shay JW, Wright WE. Tissue culture as a hostile environment: identifying conditions for breast cancer progression studies. Cancer Cell 2007; 12: 100-101.

11. Kuilman T, Michaloglou C, Mooi WJ, Peeper DS. The essence of senescence. Genes Dev 2010; 24: 2463-2479.

12. Smith JR, Whitney RG. Intraclonal variation in proliferative potential of human diploid fibroblasts: stochastic mechanism for cellular aging. Science 1980; 207: 82-84.

13. Bayreuther K, Rodemann HP, Hommel R, Dittmann K, Albiez M, Francz PI. Human skin fibroblasts in vitro differentiate along a terminal cell lineage. Proc Natl Acad Sci USA 1988; 85: 5112-5116.

14. Harley $\mathrm{CB}$, Futcher $\mathrm{AB}$, Greider $\mathrm{CW}$. Telomeres shorten during ageing of human fibroblasts. Nature 1990; 345: 458-460.

15. Cawthon RM, Smith KR, O'Brien E, Sivatchenko A, Kerber RA. Association between telomere length in blood and mortality in people aged 60 years or older. Lancet 2003; 361: 393-395.

16. Allsopp RC, Vaziri H, Patterson C, Goldstein S, Younglai EV, Futcher AB et al. Telomere length predicts replicative capacity of human fibroblasts. Proc Natl Acad Sci USA 1992; 89: 10114-10118.

17. Richter T, von Zglinicki T. A continuous correlation between oxidative stress and telomere shortening in fibroblasts. Exp Gerontol 2007; 42: 1039-1042.

18. von Zglinicki T, Saretzki G, Docke W, Lotze C. Mild hyperoxia shortens telomeres and inhibits proliferation of fibroblasts: a model for senescence? Exp Cell Res 1995; 220 : 186-193.

19. Greider CW, Blackburn EH. Identification of a specific telomere terminal transferase activity in Tetrahymena extracts. Cell 1985; 43(2 Pt 1): 405-413.

20. von Zglinicki T, Petrie J, Kirkwood TB. Telomere-driven replicative senescence is a stress response. Nat Biotechnol 2003; 21: 229-230.

21. Vaziri H, Dragowska W, Allsopp RC, Thomas TE, Harley CB, Lansdorp PM. Evidence for a mitotic clock in human hematopoietic stem cells: loss of telomeric DNA with age. Proc Natl Acad Sci USA 1994; 91: 9857-9860.

22. Simonsen JL, Rosada C, Serakinci N, Justesen J, Stenderup K, Rattan SI et al. Telomerase expression extends the proliferative life-span and maintains the osteogenic potential of human bone marrow stromal cells. Nat Biotechnol 2002; 20: 592-596.

23. Boker W, Yin Z, Drosse I, Haasters F, Rossmann O, Wierer M et al. Introducing a singlecell-derived human mesenchymal stem cell line expressing hTERT after lentiviral gene transfer. J Cell Mol Med 2008; 12: 1347-1359.

24. Maser RS, DePinho RA. Connecting chromosomes, crisis, and cancer. Science 2002; 297 565-569.

25. Martinez $\mathrm{P}$, Blasco MA. Telomeric and extra-telomeric roles for telomerase and the telomere-binding proteins. Nat Rev Cancer 2011; 11: 161-176.

26. Sareen D, McMillan E, Ebert AD, Shelley BC, Johnson JA, Meisner LF et al. Chromosome 7 and 19 trisomy in cultured human neural progenitor cells. PLoS One 2009; 4: e7630.

27. Estrada JC, Albo C, Benguria A, Dopazo A, Lopez-Romero P, Carrera-Quintanar L et al. Culture of human mesenchymal stem cells at low oxygen tension improves growth and genetic stability by activating glycolysis. Cell Death Differ 2011; 19: 743-755.

28. Ben-David U, Mayshar Y, Benvenisty N. Large-scale analysis reveals acquisition of lineage-specific chromosomal aberrations in human adult stem cells. Cell Stem Cell 2011; 9: $97-102$.

29. Laurent LC, Ulitsky I, Slavin I, Tran H, Schork A, Morey R et al. Dynamic changes in the copy number of pluripotency and cell proliferation genes in human ESCs and iPSCs during reprogramming and time in culture. Cell Stem Cell 2011; 8: 106-118.

30. Spits C, Mateizel I, Geens M, Mertzanidou A, Staessen C, Vandeskelde Y et al. Recurrent chromosomal abnormalities in human embryonic stem cells. Nat Biotechnol 2008; 26 : 1361-1363.

31. Bernardo ME, Zaffaroni N, Novara F, Cometa AM, Avanzini MA, Moretta A et al. Human bone marrow derived mesenchymal stem cells do not undergo transformation after longterm in vitro culture and do not exhibit telomere maintenance mechanisms. Cancer Res 2007; 67: 9142-9149.

32. Garcia S, Bernad A, Martin MC, Cigudosa JC, Garcia-Castro J, de la Fuente R. Pitfalls in spontaneous in vitro transformation of human mesenchymal stem cells. Exp Cell Res 2010; 316: 1648-1650.

33. Izadpanah R, Kaushal D, Kriedt C, Tsien F, Patel B, Dufour J et al. Long-term in vitro expansion alters the biology of adult mesenchymal stem cells. Cancer Res 2008; 68 : 4229-4238.

34. Torsvik A, Rosland GV, Svendsen A, Molven A, Immervoll H, McCormack E et al. Spontaneous malignant transformation of human mesenchymal stem cells reflects crosscontamination: putting the research field on track - letter. Cancer Res 2010; 70 6393-6396.

35. Stenderup K, Justesen J, Clausen C, Kassem M. Aging is associated with decreased maximal life span and accelerated senescence of bone marrow stromal cells. Bone 2003 33: $919-926$

36. Lawless C, Jurk D, Gillespie CS, Shanley D, Saretzki G, von Zglinicki T et al. A stochastic step model of replicative senescence explains ROS production rate in ageing cell populations. PLoS One 2012; 7: e32117.

37. Kim TH, Xiong $\mathrm{H}$, Zhang Z, Ren $\mathrm{B}$. beta-Catenin activates the growth factor endothelin-1 in colon cancer cells. Oncogene 2005; 24: 597-604. 
38. Guerriero R, Mattia G, Testa U, Chelucci C, Macioce G, Casella I et al. Stromal cell-derived factor 1alpha increases polyploidization of megakaryocytes generated by human hematopoietic progenitor cells. Blood 2001; 97: 2587-2595

39. Keryer G, Witczak O, Delouvee A, Kemmner WA, Rouillard D, Tasken K et al. Dissociating the centrosomal matrix protein AKAP450 from centrioles impairs centriole duplication and cell cycle progression. Mol Biol Cell 2003; 14: 2436-2446.

40. Nelson J, Bagnato A, Battistini B, Nisen P. The endothelin axis: emerging role in cancer Nature Rev Cancer 2003; 3: 110-116.

41. Zunino R, Li Q, Rose SD, Romero-Benitez MM, Lejen T, Brandan NC et al. Expression of scinderin in megakaryoblastic leukemia cells induces differentiation, maturation, and apoptosis with release of plateletlike particles and inhibits proliferation and tumorigenesis. Blood 2001; 98: 2210-2219.

42. Saksela E, Moorhead PS. Aneuploidy in the degenerative phase of serial cultivation of human cell strains. Proc Natl Acad Sci USA 1963; 50: 390-395.

43. Peterson SE, Westra JW, Rehen SK, Young H, Bushman DM, Paczkowski CM et al. Normal human pluripotent stem cell lines exhibit pervasive mosaic aneuploidy. PLoS One 2011; 6: e23018.

44. Baker DE, Harrison NJ, Maltby E, Smith K, Moore HD, Shaw PJ et al. Adaptation to culture of human embryonic stem cells and oncogenesis in vivo. Nat Biotechnol 2007; 25: 207-215.

45. Wang E. Senescent human fibroblasts resist programmed cell death, and failure to suppress bcl2 is involved. Cancer Res 1995; 55: 2284-2292.

46. Sharma NK, Reyes A, Green P, Caron MJ, Bonini MG, Gordon DM et al. Human telomerase acts as a hTR-independent reverse transcriptase in mitochondria. Nucleic Acids Res 2011; 40: 712-725.

47. Indran IR, Hande MP, Pervaiz S. hTERT overexpression alleviates intracellular ROS production, improves mitochondrial function, and inhibits ROS-mediated apoptosis in cancer cells. Cancer Res 2011; 71: 266-276.

48. Choi J, Southworth LK, Sarin KY, Venteicher AS, Ma W, Chang W et al. TERT promotes epithelial proliferation through transcriptional control of a Myc- and Wnt-related developmental program. PLoS Genet 2008; 4: e10.
49. Haendeler J, Drose S, Buchner N, Jakob S, Altschmied J, Goy C et al. Mitochondrial telomerase reverse transcriptase binds to and protects mitochondrial DNA and function from damage. Arterioscler Thromb Vasc Biol 2009; 29: 929-935.

50. Maida Y, Yasukawa M, Furuuchi M, Lassmann T, Possemato R, Okamoto N et al. An RNAdependent RNA polymerase formed by TERT and the RMRP RNA. Nature 2009; 461: 230-235.

51. Coppe JP, Patil CK, Rodier F, Sun Y, Munoz DP, Goldstein J et al. Senescence-associated secretory phenotypes reveal cell-nonautonomous functions of oncogenic RAS and the p53 tumor suppressor. PLoS Biol 2008; 6: 2853-2868.

52. Freund A, Orjalo AV, Desprez PY, Campisi J. Inflammatory networks during cellular senescence: causes and consequences. TrendsMol Med 2010; 16: 238-246.

53. Shelton DN, Chang E, Whittier PS, Choi D, Funk WD. Microarray analysis of replicative senescence. Curr Biol 1999; 9: 939-945.

54. Beausejour CM, Krtolica A, Galimi F, Narita M, Lowe SW, Yaswen P et al. Reversal of human cellular senescence: roles of the p53 and p16 pathways. EMBO J 2003; 22: 4212-4222.

55. Herbert BS, Hochreiter AE, Wright WE, Shay JW. Nonradioactive detection of telomerase activity using the telomeric repeat amplification protocol. Nat Protoc 2006; 1: 1583-1590.

56. Levine RL, Williams JA, Stadtman ER, Shacter E. Carbonyl assays for determination of oxidatively modified proteins. Methods Enzymol 1994; 233: 346-357.

57. Wong SH, Knight JA, Hopfer SM, Zaharia O, Leach CN Jr., Sunderman FW Jr. Lipoperoxides in plasma as measured by liquid-chromatographic separation of malondialdehyde-thiobarbituric acid adduct. Clin Chem 1987; 33(2 Pt 1): 214-220. published by Nature Publishing Group. This work is licensed under a Creative Commons Attribution-NonCommercialNoDerivs 3.0 Unported License. To view a copy of this license, visit http://creativecommons.org/licenses/by-nc-nd/3.0/

Supplementary Information accompanies this paper on Cell Death and Disease website (http://www.nature.com/cddis) 